\title{
Spectroscopic Studies of Gel Grown Barium Mixed Magnesium Oxalate Crystal
}

\author{
Mangala M Sanjeevannanavar ${ }^{l}$, Jagannatha $N .^{1, *}$ \\ ${ }^{I} P$ G Department of Physics, FMKMC College, A Constituent College of Mangalore University, \\ Madikeri-571201, Kodagu, Karnataka, India \\ Email: jagannathnettar@yahoo.co.in
}

\begin{abstract}
Barium mixed Magnesium Oxalate (BMO) crystals were grown successfully by silica hydrogel technique. Crystals were optimized by various parameters. Grown crystals were studied using the spectroscopic techniques which included FESEM, EDAX, FTIR and Raman spectrometer. Field Emission Scanning Electron Microscope (FESEM) reveals morphology of BMO crystal. Characterization of Energy Dispersive $\mathrm{X}$-Ray Analysis (EDAX) shows the presence of $\mathrm{Mg}, \mathrm{Ba}, \mathrm{O}$ and carbon elements in the crystal. The presence of functional groups in the grown crystal was confirmed by Fourier Transmission Infrared (FTIR) spectrometer and Raman spectrometer.
\end{abstract}

Keywords: BMO, Crystal, FESEM, EDAX, FTIR and Raman spectrometer

\section{Introduction}

Single crystals are of great interest for their important applications such as optical data storage technology, telecommunications, optical electronics, laser frequency shifting, amplitude modulation, phase modulation $[1,2]$. Now a days significant attention has been paid to growth of mixed single crystals because of their perfect electrical and optical properties, they influence on growth parameters, growth kinetics and morphology of single crystals [3,4]. Many nonlinear optical devices fabricated by using single crystals based on their optical transmission characteristics [5]. Intensity of nonlinear optical material defends on refractive index and absorption coefficient which is very useful application for optical devices [6]. Present paper describes Barium mixed Magnesium oxalate single crystals were grown by silica gel technique. Silica gel method gained good attention because of its simplicity and inexpensive and crystals were grown at ambient temperature [7]. Oxalate crystals also played very important role in many technologies such as ferroelectric, magnetic and super conducting materials $[8,9]$. Surface morphology of grown crystals was studied by using Field Emission Scanning Electron Microscope. The elements present in the crystals were identified by Energy Dispersive X-Ray Analysis. Spectroscopic studies done successfully by FTIR and Raman spectrometer it reveals modes of water molecules, carboxylic group and metal oxide bonds.

\section{Experimental methods}

10 INTERNATIONAL JOURNAL OF INNOVATIVE RESEARCH IN PHYSICS 
The Barium mixed Magnesium oxalate (BMO) crystals were grown by silica gel technique. The chemicals Sodium Meta Silicate $\left(\mathrm{Na}_{2} \mathrm{SiO}_{3}\right)$, solution of oxalic acid $\left(\mathrm{C}_{2} \mathrm{H}_{2} \mathrm{O}_{4} \cdot 2 \mathrm{H}_{2} \mathrm{O}\right)$, solution of Barium chloride $\left(\mathrm{BaCl}_{2} \cdot 2 \mathrm{H}_{2} \mathrm{O}\right)$ and Magnesium chloride $\left(\mathrm{MgCl}_{2} \cdot 6 \mathrm{H}_{2} \mathrm{O}\right)$ were used in growth process. Gel was prepared by dissolving solution of oxalic acid in the solution of Sodium Meta Silicate of specific gravity $1.038 \mathrm{~g} / \mathrm{cc}$. Prepared gel solution was stored in the different test tubes of $15 \mathrm{~cm}$ length and $1.5 \mathrm{~cm}$ diameter. After 4 to 5 days gel was set in the test tubes. The concentration of solution of oxalic acid was $0.5 \mathrm{M}$. Mixture of Barium chloride solution and Magnesium chloride solution was poured along the sides of the gel contained test tubes. Concentration of barium chloride solution and magnesium chloride solution was $0.5 \mathrm{M}$. Crystals were grown inside the test tube after 20days. Maximum sized, good quality crystals were yielded. Fig. 1 shows grown crystals.

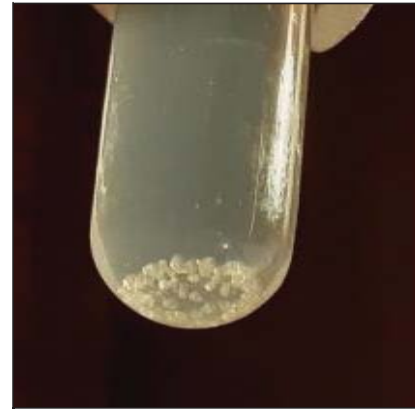

(a)

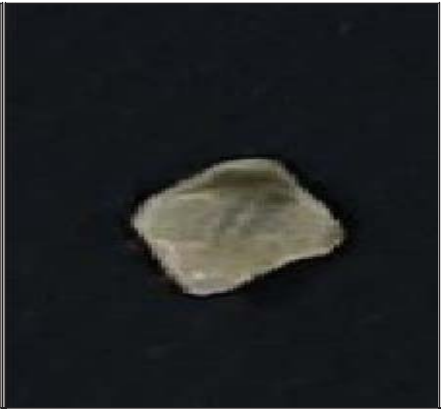

(b)

FIG 1. a) Growth of Barium Magnesium oxalate crystals and b) Extracted BMO crystals

\section{Results and Discussion}

a. Crystal growth

The effect of the various growth parameters such as gel density, concentration of oxalic acid solution, concentration of Barium chloride solution, concentration of Magnesium chloride solution and gel setting time were optimized to get good quality crystals. The optimized conditions were recorded and shown in Table 1.

Table 1. Optimum condition for growth of BMO crystals

\begin{tabular}{ll}
\hline Parameters & Optimization condition \\
\hline Gel density & $1.038 \mathrm{~g} / \mathrm{cc}$ \\
Concentration of oxalic acid & $0.5 \mathrm{M}$ \\
Concentration of $\mathrm{BaCl}_{2}$ & $0.5 \mathrm{M}$ \\
Concentration of $\mathrm{MgCl}_{2}$ & $0.5 \mathrm{M}$ \\
Gel setting time & 4 to 5 days \\
Crystal formation time & 20 days \\
\hline
\end{tabular}

11 INTERNATIONAL JOURNAL OF INNOVATIVE RESEARCH IN PHYSICS 
b. Field Emission Scanning Electron Microscope and Energy Dispersive X-ray Analysis

Field emission scanning electron microscope reveals the morphology of grown crystal is shown in Fig.2. The study of the surface morphology of the crystal gives valuable information about its internal structure. Micro crystals and rod shaped units attached to the surface of the crystals was observed [10,11]. Energy dispersive X-ray analysis spectrum confirms the presence of essential elements Magnesium, Barium, Oxygen and Carbon in the crystals. Atomic and weight percentage of the composed elements are studied by the EDAX.

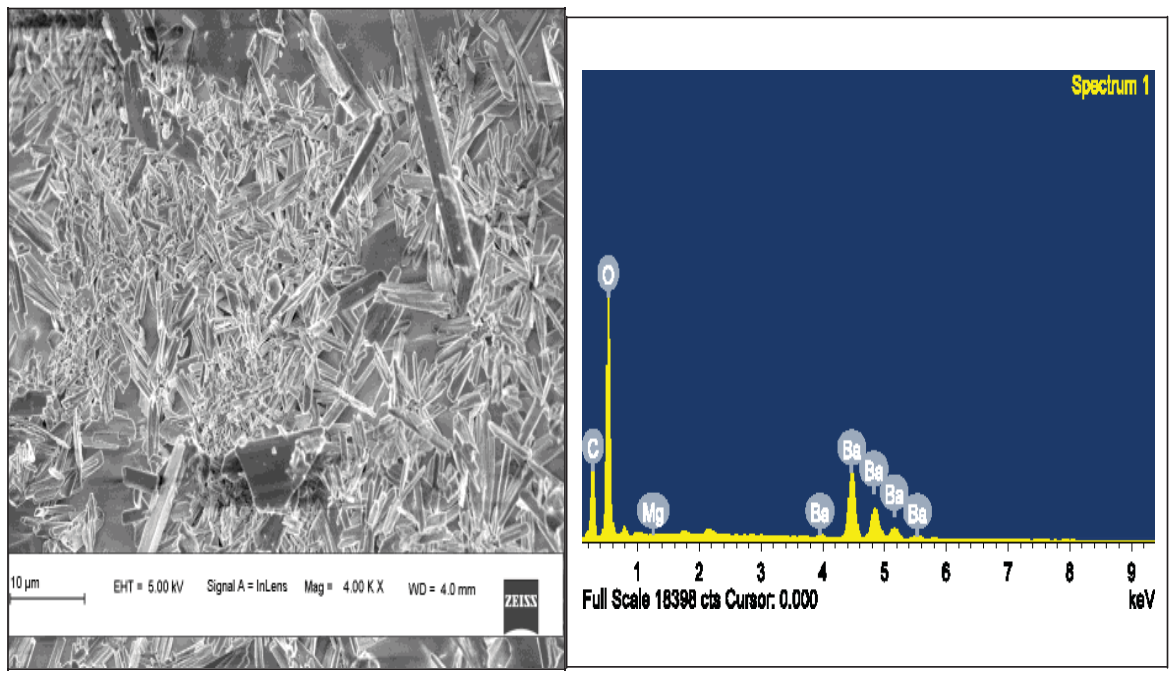

(a)

(b)

FIG 2. a) FESEM image of BMO crystal b) Electron spectra of BMO crystals

Table 2. Chemical composition of BMO crystal

\begin{tabular}{lcc}
\hline Elements & Weight $\%$ & Atomic $\%$ \\
\hline $\mathrm{O}$ & 52.50 & 60.30 \\
$\mathrm{Mg}$ & 0.18 & 0.13 \\
$\mathrm{Ba}$ & 70.32 & 9.41 \\
$\mathrm{C}$ & 19.70 & 30.15 \\
\hline
\end{tabular}

\section{c. Fourier Transform Infrared (FTIR)}

The Barium mixed Magnesium Oxalate crystal analyzed by Fourier Transform Infrared (FTIR) Shown in Fig.3. The spectrum of FTIR recorded in the region 0 to $4000 \mathrm{~cm}^{-1}$ shows different functional groups present in the grown crystal. The peaks from $3757.78 \mathrm{~cm}^{-1}$ to $2967.58 \mathrm{~cm}^{-1}$ is assigned to the symmetric and asymmetric stretching of $\mathrm{O}-\mathrm{H}$ group modes of water molecules $[12,13]$. The strong asymmetric band at $1577.86 \mathrm{~cm}^{-1}$ corresponds to $\mathrm{C}=\mathrm{O}$ stretch of carbonyl group. The sharp peak at $1306.09 \mathrm{~cm}^{-1}$ is attributed to 
the asymmetric stretching of C-O group. The peaks at $747.12 \mathrm{~cm}^{-1}$ and $505.33 \mathrm{~cm}^{-1}$ indicates $\mathrm{M}-\mathrm{O}$ stretching mode $[14,15]$.

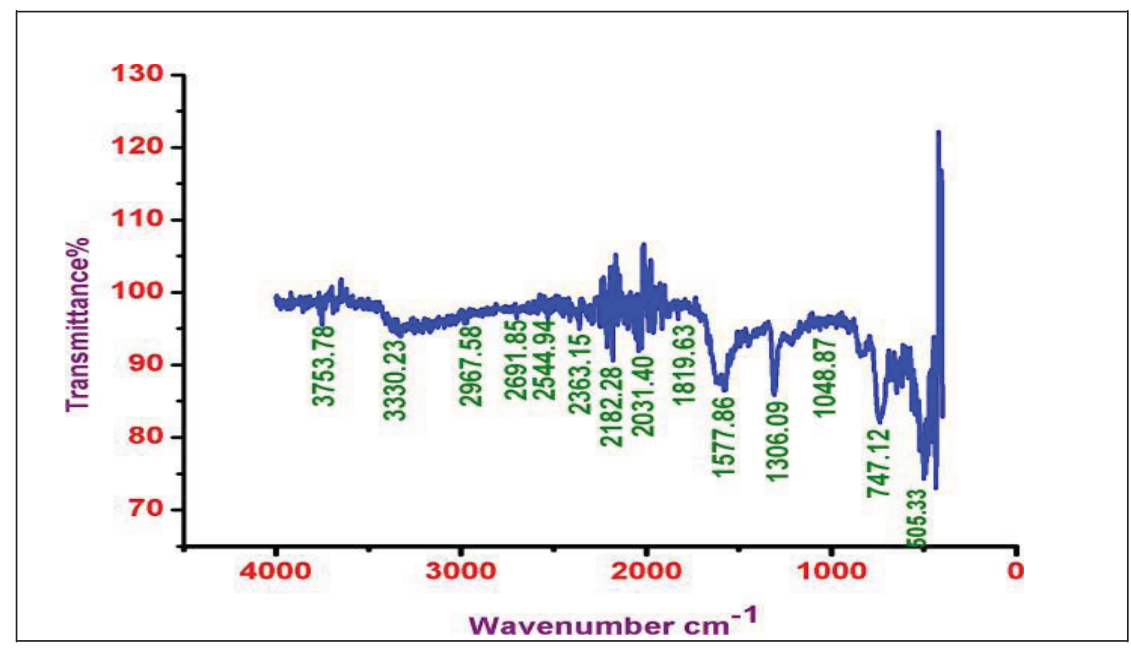

FIG 3. FTIR spectra of BMO crystal

\section{d. Laser Raman spectrometer}

Fig.4 shows the laser Raman spectrum of BMO crystal was recorded in the range 0 to $4000 \mathrm{~cm}^{-1}$. The spectrum shows weak peaks at $3834.89 \mathrm{~cm}^{-1}$ and $3341.02 \mathrm{~cm}^{-1}$ which are assigned to symmetric and asymmetric stretching of $\mathrm{O}-\mathrm{H}$ band. The peak at $2801.18 \mathrm{~cm}^{-1}$ corresponds to $\mathrm{C}-\mathrm{H}$ band of symmetric vibration [16,17]. The broad band at $1557.49 \mathrm{~cm}^{-1}$ and sharp band at $1468.27 \mathrm{~cm}^{-1}$ confirms asymmetric and symmetric stretching vibration of the carboxylate group respectively. The peak at $883.38 \mathrm{~cm}^{-1}$ confirms presence of C-C vibration. Weak band at $494.05 \mathrm{~cm}^{-1}$ and medium band at $134.46 \mathrm{~cm}^{-1}$ assigned to stretching vibration of M-O bands $[18,19]$.

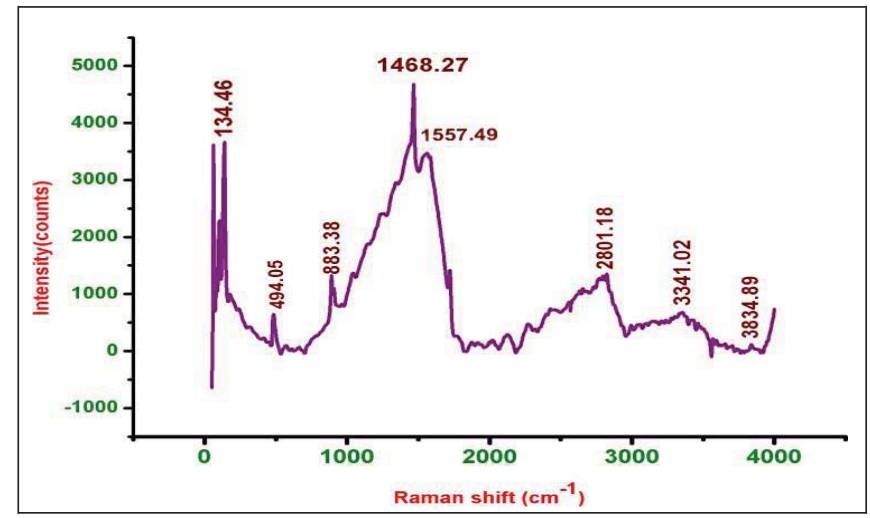

FIG 4. Raman spectra of BMO crystal 


\section{Conclusion}

The Barium mixed Magnesium Oxalate crystals were successfully grown by silica gel technique. Crystals were optimized by various parameters. Surface morphology analyzed by FESEM characterization. Elements present in the crystals were confirmed by the EDAX. The functional groups present in the crystal indentified by FTIR spectrum and laser Raman Spectrum.

\section{Acknowledgements}

The authors are thankful to the scientific officer DST-PURSE laboratory Mangalore University, Karnatak and UPE University of Mysore, Manasagangothri, Karnatak for providing research facilities during the course of this work. Authors are also grateful to Mangalore University for sanction of scholarship facility.

\section{REFERENCES}

[1] H. K. Henisch, Crystal Growth in Gels, Pennsylvania State University Press, State College, PA,(1970)

[2] S.Chandra, R.Paulraj, P.Ramaswamy, optical materials 73, 154-162(2017).

[3] V. Mathivanan, M. Haris, A Spectrochimica Acta Part A: Molecular and Biomolecular Spectroscopy 102, $341-349(2013)$

[4] N. Jagannatha, P. Mohan Rao, Bull. Mater, Sci 16, 365-370(1993).

[5] M M Sanjeevannanavar, N.Jagannatha, P.S.Rohith, AIP Conference Proceedings 2269, 030008 (2020)

[6] K.J. Arun, S. Jayalekshmy PHOTONICS LETTERS OF POLAND 7, 81-83 (2015)

[7] S K Bachhav, P A Savale, S T Pawar, Advances in Applied Science Research 1, 26-33(2010)

[8] G.Vimal, Kamal P Mani, Gijo Jose, P R Biju, Cyriac Joseph, N.V. Unnikrishnan, M.A.Ittyachen, Journal of crystal growth 404, 20-25(2014)

[9] Mangala M Sanjeevannanavar, N Jagannatha, P S Rohith AIP Conference Proceedings 2220, 060009 (2020)

[10] V.B.Suryavanshi, R.T.Chaudari, Indian Journal of Material Science, 2014

[11] P.S Rohith, N. Jagannatha, Journal of Applicable Chemistry 8,1838-1844(2019).

[12] M.R.Shedam,Rakesh M.Shedam, Shridhar N Matha., Acta chemical IASI 25, 195-207 (2017).

[13] P.S. Rohith, N. Jagannatha, K V Pradeepkumar, M S Mangala, Journal of Physics: conference series, 1495, 012005(2020) 
[14] R.G.Vidya, R.Ramaswamy, L.Vijayalakshmi., IJPR, 3, 97-100(2013)

[15] K V Pradeepkumar, N Jagannatha, Journal of Applicable chemistry. 8(4), 1893-1899, (2019)

[16] Jyoti Dalal, Binay Kumar., Optical Materials 51, 139-147(2016)

[17] C.Beekaman, A.A.Reijnders, Y.S.Oh, S.W.Cheong, K.S.Burch,Phys RevB 86, 020403(2012)

[18] M M Sanjeevannanavar, N.Jagannatha, P.S.Rohith, Journal of Physics and chemistry of materials 7, 01-04(2020)

[19] C.Muthuselvi, M.Dhavachitra, S.Pandiarajan, Journals of Chemical and Pharmaceutical resaech 8, 804-814 (2016) 